Academic Platform Journal of Engineering and Science

\title{
Bir Lastik Fabrikasında Dinamik Adresleme Yaklaşımı ile Depoya Yerleştirme
}

\author{
*1 Berrin Denizhan, ${ }^{2}$ Şeyma Menşur, \\ ${ }^{1}$ Sakarya Üniversitesi, Endüstri Mühendisliği Bölümü, denizhan@sakarya.edu.tr, \\ ${ }^{2}$ Sakarya Üniversitesi Endüstri Mühendisliği Bölümü, seymamensur@outlook.com, iD \\ Araştırma Makalesi \\ Geliş Tarihi: 29.01.2019 \\ Kabul Tarihi: 17.09 .2019
}

\section{$\ddot{\mathbf{O} z}$}

Depo yönetiminin etkinliğini belirleyen en önemli unsurlardan biri deponun tasarımı ve doğru adresleme/yerleştirme yapılabilmesidir. Kurulan depo sahasının, işletmenin gereksinimlerine göre tasarlanmadığı durumlarda, depo sahası-operasyon uyumsuzluğu doğmakta, söz konusu durum yüksek stok maliyeti, düşük verimlilik ve düşük üretim performansı ve işlerin aksaması ile de sonuçlanabilmektedir. Bu sebeple depo tasarımında, depo sahasının mimari yapısı, depo sahasındaki yerleşim, yükleme, boşaltma ve istifleme sahalarının yerleşimi gibi faktörler doğrudan etkili olmaktadır. Yapılan bu çalışmada bir lastik üreticisindeki üretim ortamı incelenmiştir. Mikser sahasındaki peronlara malzemelerin doğru yerleştirilememesi, depo alanı kullanımında verimsizliğe ve yetersizliğe sebep olmaktadır. Bu sebeple depodaki stok kapasitesi ve kapasite kullanımındaki verimlilik artırılmaya çalışılmıştır. Yapılan analizler sonucunda bu probleme en uygun çözüm olarak statik adreslemeden dinamik adreslemeye geçiş olduğu önerilmiştir. Dinamik adresleme için bir algoritma geliştirilmiştir. Algoritma Visual Basic dilinde dinamik programlama yöntemi kullanılarak kodlanmıştır. Hem mevcut durum olan statik adresleme hem de önerilen durum olan dinamik adresleme için yazılan program çıtıları karşılaştırıldığında; işletmeye yarı dolu peron sayısının azaltılması yönünden statik adreslemede \%88 olan oranın dinamik adresleme ile \%53'e kadar iyileştirme olanağ1 sunabildiği görülmüştür. Ayrıca statik adreslemede kullanılabilir peron sayısı 213 iken dinamik adresleme sayesinde bu sayı 269 olup, işletmeye yeni karışım kodlarının depolanması için fırsat sunulmuştur. Son olarak ise Mikser'den çıkan paletlere peron ararken dinamik adreslemede göz önünde bulundurulan "Miksere en yakın perona ata” stratejisi ile forkliftçi iş yükü azaltılmıştır.

Anahtar Kelimeler: Depo yönetimi, dinamik programlama, dinamik adresleme

\section{Warehouse Allocation in a Tire Factory with Dynamic Addressing}

\author{
*1 Berrin Denizhan, ${ }^{* 2}$ Şeyma Menşur, \\ ${ }^{1}$ Sakarya Üniversitesi, Endüstri Mühendisliği Bölümü, denizhan@sakarya.edu.tr \\ ${ }^{2}$ Sakarya Üniversitesi Endüstri Mühendisliği Bölümü, seymamensur@outlook.com
}

\begin{abstract}
The design of the warehouse and the correct addressing/placement is one of the most critical factors to the efficiency of warehouse management. In cases where the established storage area is not designed to meet the requirements of the enterprise, the warehouse site-operation mismatch arises, which can result in high inventory costs, low productivity and low production performance and disruption of the works. Because of this, factors such as the architectural structure of the warehouse area, settlement in the storage, loading, unloading, and placement of the stacking areas are directly effective in warehouse design. In this study, the production environment of a tire manufacturer is examined. The mixer area makes the storage area insufficient due to the inability to place the materials correctly on the platforms. Therefore, the stock capacity and the efficiency of capacity utilization in the warehouse have been increased. As a result of the analysis, it has been suggested that the transition from static addressing to dynamic addressing is the most appropriate solution to this problem. An algorithm for dynamic addressing has been developed. The algorithm is coded using the dynamic programming method in visual basic language. The output of the program was compared for both the current state of static addressing and the proposed state of dynamic addressing. It was seen that the number of half-loaded platforms could improve with a decrease of $88 \%$ in static addressing and up to $53 \%$ in dynamic addressing. In addition, while the number of platforms available for static addressing was 213, this was 269 thanks to dynamic
\end{abstract}


addressing. This allows the facility to store new mix codes. Lastly, the forklift assign to the platform "closest to the mixer "strategy, which is considered in dynamic addressing when searching for platforms for the pallets exiting the mixer, has reduced the workload of the forklift truck.

Keywords: Warehouse, dynamic programming, dynamic addressing

\section{GİRIŞ}

Depoya yerleştirme bütün üretim sürecinin performansını etkileyen unsurlardan biridir. Doğru yerleştirme üretim sürecine doğru miktarlarda ürünün akışını hızlandırmakta, yanlış yerleştirme ise çevrim süresini artırarak malzeme yokluğu yaşanmasına sebep olabilmektedir. Makaleye konu olan problem lastik üretiminin ilk aşaması olan karışımın hazırlanması işleminin gerçekleştiği mikser makinelerini ve hazırlanan karışımın istiflendiği Wigwag ekipmanlarını kapsamaktadır. İşletmedeki ana sorun, Wigwag ekipmanı ile istiflenen paletin götürüldüğü Mikser son karışım stok alanlarının verimli olarak kullanılamamasıdır. Stoklama alanlarındaki bahsedilen verimsizliğin sebeplerinin belirlenmesi için gözlemler yapılmıştır. Yapılan gözlemler sonunda verimliliği azaltan birkaç farklı sebep bulunmaktadır. $\mathrm{Bu}$ makalede ise verimliliği azaltan sebeplerden biri olan sabit adresleme politikasına çözüm önerilmiştir. Sabit adresleme politikasıyla ilgili yapılan araştırmalar sonucunda elde edilen bilgiler ve işletmedeki durum hakkında bilgi verilmiştir.

Sabit yerleştirme sistemine göre her mal ya da mamulün sabit bir adresi vardır ve değişmez. Bu işleyiş aşağıdaki gibi bazı problemler oluşturabilir.

1. Her yeni malzeme için, bölümlerde fazladan alan bulundurulması gerekmektedir. Ayrıca her malzemenin yerinde olabilmesi ve tekrar yerleştirme işlemlerinin oluşmaması için, her zaman boş bir depolama kapasitesine ihtiyaç vardır.

2. Farklı özellikleri olan malzemelerin depolanma ya da elde tutabilme koşullarını göz önüne almayabilir ve depolanması zor olan malzeme sistemin dişında tutulur.

3. Sık kullanılan malzemeler için personele ve ihtiyaca cevap verme kolaylığı bakımından herhangi bir strateji uygulanmayabilir.

İşletmede sabit adreslemenin sorun olmasının sebebi, her peronun belirlenmiş karışım kodlarına göre isimlendirilmiş olmasıdır. Her kod, sadece kendi karışım koduna sahip perona bırakılabilmektedir. Bu sebeple, üretimde olmayan bir koda da ait, başka kodlar tarafından kullanılamayan peronlar bulunmaktadır. $\mathrm{Bu}$ da aslında var olan fakat kullanılamayan kapasite demektir. Bahsedilen bu dezavantajları nedeniyle sabit adresleme politikası kapasite kullanım oranını azaltan bir durumdur.

Rekabetin artması ile birlikte depolama, önemli bir rekabet avantaj1 haline gelmiştir. Malzeme girişi ve bitmiş ürün teslimatı ve hareketleri sırasındaki bütün faaliyetler depoyu doğrudan etkileyerek maliyet yaratmaktadır. $\mathrm{Bu}$ süreçte maliyet azaltıcı depo hareketlerinin planlanması, yerleştirme adresleme ve sipariş toplama süreçlerindeki iyileştirmeler büyük maiyet avantajı da sağlamaktadır. Aynı zamanda depolama sistemleri ve hangi malzemelerin nasıl depolanacağının, iletileceğinin bilinmesi, zaman ve enerji tasarrufu da sağlanmaktadır [8].

İşletmeler ise ellerinde her zaman müşteri taleplerini karşılayabilmek için mal bulundururlar. Dolayısıyla depolamaya ihtiyaç duyarlar çünkü mevcut ürünlerle bu ürünlere olacak talebi bire bir örtüştürmek mümkün değildir. Birçok sebepten dolayı elimizdeki kaynak miktarı ve bu kaynağa olacak olan talep s1k sık değişmektedir ve bu değişkenlik elde bulundurma yani depolama ihtiyacını oluşturmaktadır [13].

Depolama süreci içindeki en önemli faaliyetlerden biri depo alanının aktif kullanımı ve bunu sağlayacak doğru adreslemenin yapılabilmesidir. Bu sebeple ürünlerin raflara yerleştirmesi bir çizelgeleme problemi olarak ele alınabilir. Depoya yerleştirilecek ürün ve rafların özellikleri ve öncelikleri sıralama ve çizelgeleme kurallarından faydalanılarak oluşturulabilir. Bu sebeple bir dizi işin hangi sırayla işleme alınacağına karar verilmesi gereken her durum bir çizelgeleme problemi olarak ele alınabilir. Depolama ve depolamanın nasıl, hangi şekilde, hangi sırayla yapılacağını planlayan çizelgeleme yöntemleri de literatürde yer almaktadır. Dolayısıyla çizelgeleme problemleri sadece üretim sistemlerinde değil, taşıma ve dağıtım, iletişim, bilgi sistemleri gibi farklı sistemlerde de ortaya çıkmaktadır [5].

Çizelgeleme problemleri işlerin çizelgeleme boyunca hazır bulunma durumuna göre statik ve dinamik olarak ikiye ayrılır. Çalışma zamanı boyunca işlerin sayısı değişmezse sistem statik, yeni işler sisteme dahil edilirse dinamik olarak adlandirılır [4].

İmalat ve servis endüstrilerinde çizelgeleme bir karar verme prosesidir. Matematiksel veya sezgisel yöntemler kullanılarak görevlerin sınırlı kaynaklara atanması işlemi olarak gerçekleştirilmektedir. Bu atama, iş önceliği ve diğer faktörlere göre sıralama yapılarak işletmelerin belirlenen amaca ulaşması sağlanır. Bu amaçlar kimi zaman toplam çevrim süresinin kısaltılması, kimi zaman geciken işlerin sayılarının azaltılması ve beklemelerin azaltılması gibi performans ölçütleri ile belirlenir.

Çizelgeleme, parametrelerin deterministik veya belirsiz olduğu durumu, tek makinalı veya çoklu makine, geliş sürecinin statikten veya dinamik olarak değiştiği çeşitli problem yapılarını kapsar [6]. Bu yöntem bütün sistemler üzerine uyarlanarak bir makine atama problemi olmasa da işlerin sıralanması ve çizelgelenmesinde kullanılabilir. 
Çizelgeleme probleminin ilk tartışılmaya başlandığ zamanlar 20. yüzyılın başlarına kadar uzanır. İlk çözüm algoritmaları kombinatoryal analiz kullanılarak geliştirilmiştir. Genel kanı, Johnson 1954 tarafından yayınlanan çalışmanın çizelgelemenin yöneylem araştırması içerisinde bağımsız bir alan olarak ele alındığı ilk çalışma olduğu yönündedir [10]. Kombinatoryal analiz ile başlayan çalışmalar, dal sınır algoritmaları, Lagrangian gevşemesi gibi matematiksel programlama teknikleri, yaklaşım algoritmaları ve yerel arama sezgiselleri, meta sezgiseller ve hipersezgiseller gibi sezgisel algoritmalar ile günümüzde de ilerlemeye devam etmektedir. Literatürde öncelik kuralları ya da çizelgeleme kuralları olarak da geçen dağıtım kuralları, uygulama kolaylığı, ani değişimlere hızlı tepki verebilme yeteneği ve istenen sürede geçerli sonuç üretebilme kabiliyeti ile çizelgeleme problemlerinin çözümünde sıklıkla kullanılan sezgisel kurallardır [1]. Çizelgeleme yöntemleri ile geciken işlerin minimuma indirilmesi, kapasitenin eksik kullanılması, üretimde yer alan darboğazlar, gibi problemler de ortadan kaldırilabilmektedir [11].

Çizelgeleme problemlerini çözmek için yaygın olarak eniyileme/optimizasyon yöntemleri ve sezgisel yöntemler kullanılmaktadır. Optimizasyon yöntemleri üç ana grupta toplanabilir. Bunlardan birincisi; dinamik programlama tekniğidir. Bu yöntem çizelgeleme ve diğer kombinatoryal problemler için kullanılan çok aşamalı karar problemidir. Bu yöntemle ilgili en önemli çalışmalar, Held ve Karp (1962) tarafından yapılmıştır. Bu teknik ile belli kısıtlayıcı kuralları uygulayarak çok sayıda aday çözümü elimine etmiştir [12]. Uygulamanın olumsuz yönü ise çok boyutlu problemlerde etkin olmamasıdır. Durum değişkenlerinin sayısı arttığında işlem sayısı artar ve bu özellik büyük boyutlu problemlerin çözümünde dinamik programlama yaklaşımının kullanımını kisitlar.

İkinci olarak en sık kullanılan yöntem dal-sınır algoritmasıdır. Dal-sınır algoritması ilk olarak 1959 yılında gezgin satıcı probleminde uygulanmıştır. $\mathrm{Bu}$ yöntemde, çözüm zamanları ve farklı veri setlerine göre değişkenlik gösterir. Dallanan değişken ile sınırlama yaklaşımının seçimi algoritmanın performansını büyük ölçüde etkiler ve problem boyutu arttıkça çözümü zorlaşmaktadır [6].

Diğer yöntem ise tamsayılı programlamadır. Araştırmacılar, çizelgeleme problemlerinin değişik kısıtları altında tamsayılı programlama modelleri geliştirmiştir. Depoya adresleme gibi dinamik problemlerin etkin bir şekilde çözümünde bu sebeple tamsayılı programlama algoritmaları başarılı değildir. Ancak birden fazla ölçütü kullanabilecek bir amaç fonksiyonu oluşturulabilir[7].

Optimizasyon teknikleri büyük boyutlu çizelgeleme problemlerinin çözümünde yetersiz kalmaktadır. Hesaplama zamanı oldukça uzundur. Aynı zamanda optimizasyon teknikleri Son yıllarda tüm bu dezavantajların giderilebileceği sezgisel yöntemler geliştirilmiştir. $\mathrm{Bu}$ sezgisel algoritmalar ise tavlama benzetimi, tabu arama, genetik algoritma ve karınca kolonisi gibi yaklaşımlardır.
Tabu Arama (TA), Glover tarafından kombinatoryal problemlerin çözümü için önerilmiş bir sezgisel programlama tekniğidir [3]. Bir katının yavaş yavaş soğutularak minimum enerji durumu elde edilene kadar fiziksel tavlama sürecini taklit eden tavlama benzetimi algoritması, olasılıklı bir arama yöntemidir. Amaç fonksiyonun değeri, azalma eğilimindedir. Bununla birlikte bazı durumlarda amaç fonksiyon değerleri yüksek olan çözümler de kabul edilmektedir. Böylece, daha iyi bir yerel minimum aramaya devam edilebilir ve yerel bir minimum çözüme takılmaktan kurtulmuş olur. Dolayısı optimizasyon problemleri için tavlama benzetimi yaklaşımı en iyi değere yakın çözümler verebilmektedir [2].

Genetik algoritma ise, doğadaki evrim yöntemlerini kullanan bir arama yöntemidir. Genetik algoritma tekniği, Michigan Üniversitesi'nde yer alan John Holland ve arkadaşlarının çalışmaları sonucu 1970'li yıllarda ortaya çıkmıştır. Genetik algoritmaların amacı karmaşık problemlerin ve çok kısıtlı problemlerin optimizasyonudur [9]. Karıncaların işbirlikçi davranışının taklidi olan karınca algoritmaları popülasyon tabanlı bir algoritmadir [13].

Yukarıda bahsedilen optimizasyon ve sezgisel yöntemler çok değişkenli depo malzemelerinde yetersiz kalmaktadır. Bunun sebebi pek çok kısıtın aynı anda kontrol edilecek olmasıdır. Bu çalışmada en iyi çözümü sunabilecek dinamik bir sezgisel oluşturulmuş ve statik adresleme ile elde edilen sonuçlar karşılaştırılmıştır.

\section{YÖNTEM}

$\mathrm{Bu}$ çalışmada bahsedilen statik adresleme politikasına çözüm olarak bir sezgisel çizelgeleme yöntemiyle dinamik adresleme algoritması oluşturulmuştur. Yeni bir sezgisel yöntemin oluşturulmasının sebebi, literatürde bulunan çizelgeleme yöntemlerinin işletme kısıtlarını karşılamada yetersiz kalmasidır.

Depoya dinamik/rastgele yerleşimde, sistematik ve çok yüksek düzeyde organize olmuş bir stok yerleştirme uygulaması vardır. Depolama stratejisi, sipariş toplama verimliliğini artırmak için öğeleri depolama konumlarına atayan bir kurallar kümesidir . Rastgele strateji, gelen paletleri rastgele olarak depolamak için mevcut boş depolama yerlerine atar ve bu da yüksek depolama kullanımı ve düşük sipariş toplama verimliliği sağlar [8].

Tüm bu avantajlar göz önüne alınarak bu makalede, firmanın mevcut durumunu benzetim modelinden ve çözüm yapan benzetim uygulamasından bahsedilmiştir. Problemin çözüm aşamaları şu şekildedir;

i- Mevcut durum ve iyileştirilecek durumun parametre, kisit ve varsayımlarının belirlenmesi.

ii- Mevcut durum olan statik adreslemenin kodlanması.

iii- İyileştirme olarak sunulan dinamik adreslemenin kodlanmas1.

iv- Programların çalıştırılarak istatistiki verilerin toplanmasi. 
v- Toplanan verilerin analiz edilerek sonuçlarının karşılaştırılması.

\section{UYGULAMA}

Problemin çözüm aşamalarına göre algoritma yazılmıştır.

\section{Așama: Mevcut durum ve iyileștirilecek durumun parametre, kısıt ve varsayımlarının belirlenmesi}

\section{Parametreler:}

Statik ve dinamik adresleme durumları için kullanılan parametreler;

- $\quad \mathrm{i}=1$ 'den i=4'e kadar a(i), b(i), c(i), d(i), f(i), g(i), h(i), j(i), k(i), l(i), m(i), n(i), o(i), p(i), r(i) parametreleri önceki günden kalan stok miktarını rastgele atayan değişkenleri temsil etmektedir.

- $\quad \mathrm{i}=1$ 'den $\mathrm{i}=40$ 'a kadar q(i) parametresi, rastgele Mikser makinelerinden çıkan palet miktarlarını temsil etmektedir.

- $\mathrm{i}=1$ 'den $\mathrm{i}=60$ 'a kadar w(i) parametresi, rastgele Mikser stok alanından çıkan palet miktarlarını temsil etmektedir.

- $\quad \mathrm{i}=1$ 'den $\mathrm{i}=60$ 'a kadar val(i) parametresi, her peronun tüm giriş ve çıkış işlemlerinin gerçekleştikten sonra elde edilen değeri temsil etmektedir.

- $\quad \mathrm{i}=1$ 'den i=60'a kadar tq(i) parametresi, peronlara günlük olarak giren palet sayılarının toplamını temsil etmektedir. tq(i) değerleri Tab2 sayfasında giriş sütunundaki alanların görülmesini sağlar.

- $\quad \mathrm{i}=1$ 'den $\mathrm{i}=60$ 'a kadar tw(i) parametresi, peronlardan günlük olarak çıkan palet sayılarının toplamını temsil etmektedir. tw(i) değerleri Tab2 sayfasında çıkış sütunundaki alanların görülmesini sağlar.

- $\quad \mathrm{i}=1$ 'den $\mathrm{i}=60$ 'a kadar cikan(i) parametresi, perondan rastgele gelen çıkış sayısından arta kalan, aynı koda sahip ve en yakın boş perona atanacak palet sayısını temsil etmektedir.

- $\mathrm{i}=1$ 'den $\mathrm{i}=60$ 'a kadar deger(i) parametresi, perona rastgele gelen giriş sayısından arta kalan ve aynı koda sahip veya en yakın boş perona atanacak palet sayısını temsil etmektedir.

\section{Kisitlar:}

Kurulan modellerdeki kapasite kısıtları şu şekilde varsayılıp, kısıt olarak göz önünde bulundurulmuştur;

- S02 stok alanında 15 peron bulunmaktadır. Her bir peronun kapasitesi 10 palettir.

- S04 stok alanında 15 peron bulunmaktadır. Her bir peronun kapasitesi 13 palettir.

- S05 stok alanında 15 peron bulunmaktadır. Her bir peronun kapasitesi 12 palettir.

- S06 stok alanında 15 peron bulunmaktadır. Her bir peronun kapasitesi 15 palettir.

Kurulan modellerdeki yapısal kısıtlar şu şekildedir;
- Her iki modelde de bir karışım kodu için art arda Mikserden çıkabilecek palet sayısı maksimum 10'dur.

- Her iki modelde de bir karışım kodu için art arda perondan çıkabilecek palet sayısı minimum 3, maksimum 10'dur.

- Statik adresleme politikasında bütün karışım kodlarının belirlenmiş adresleri bulunmaktadır ve hiçbir karışım kodu kendisine ait olmayan perona konulamamaktadır.

- Dinamik adresleme politikasında peronlara karışım kodlarının atanması işleminde ilk olarak bakılan şart, mevcut dizilişte Mikserden çıkan karışım koduyla aynı koda sahip ve kapasite olarak yeterli peron var mi? Var ise öncelikli olarak çıkan palet o perona götürülecektir. Eğer dizilişte Mikserden çıkan karışım koduyla aynı koda sahip fakat yeterli kapasiteye sahip olmayan peron var ise çıkan palet en yakın boş perona götürülecektir. Eğer mevcut diziliște Mikserden çıkan karıșım koduyla aynı kod yoksa çıkan palet en yakın boş perona götürülecektir.

- Statik ve dinamik adresleme politikalarında Mikser 1'den çıkan karışım kodları sadece S02'de depolanabilmektedir.

- Statik ve dinamik adresleme politikalarında Mikser 2'den çıkan karışım kodları sadece S04'de depolanabilmektedir.

- Statik ve dinamik adresleme politikalarında Mikser 3'den çıkan karışım kodları sadece S05'de depolanabilmektedir.

- Statik ve dinamik adresleme politikalarında Mikser 4'den çıkan karışım kodları sadece S06'da depolanabilmektedir.

- Her iki model içinde bir günde bir Mikser 'den çıkan palet miktarı minimum 110'dur.

- Her iki modelde de önceki günden kalan stok miktarları maksimum 4 olarak rastgele atanmıștır.

\section{Varsayımlar:}

- Mikser 1'den çıkan karışım kodları; H19, H28, T120, T2287, T2357, T4327, T5297, W06, W63 ve G22'dir.

- Mikser 2'den çıkan karışım kodları; T2227, T2657, T5557, T6747, T6817, T7457, T9487, W02, G34, H05'dir.

- Mikser 3'den çıkan karışım kodları; H12, H45, H55, H73, T1517, T3317, T5387, T6517, T6657, T8067'dir.

- Mikser 4'den çıkan karışım kodları; U04, W62, G50, G53, G59, G61, G72, G85, W04, W74'dür.

- Sabit adresleme politikasında perona palet girişleri ve perondan palet çıkışları rastgeledir.

- Dinamik adresleme politikasında perona girişler önce yarı dolu peronları doldurmaya/forkliftçinin yükünü azaltmak için en yakın olana bırakmaya yöneliktir. Perondan çıkışlar ise yarı dolu palet miktarını azaltmak amaçlı aynı karışım koduna sahip peronlar için daha az dolu perondan, yine aynı karışım koduna sahip eşit kapasiteli peronlar için Miksere en uzak olandan yapılmaktadır. 


\section{Aşama: Mevcut durum olan statik adreslemenin kodlanması}

Statik adresleme için yazılan programın çalışma prensibi;

Aşağıda bahsedilecek maddeler yazılan programın Tab1 kısmında gerçekleşmektedir.

- Adreslenmiş peronlara yukarıda bahsedilen a(i), b(i), c(i) vb. parametreler sayesinde rastgele maksimum 4 adet olacak şekilde önceki günden kalan palet miktarı atanır.

- Her Mikserden rastgele minimum 110 palet çıkacak şekilde palet çıkar.

- Mikserden çıkan paletler, önce yarı dolu olana ata, önce en yakın perona ata vb. gibi durumlara bakılmaksızın rastgele peronlara eklenir. Eğer rastgele gelen sayı ile peronda mevcut palet sayısının toplamı kapasiteyi aşıyorsa yine aynı karışım koduna ait adreslenmiş diğer perona aktarılır.

- Peronda bulunan paletler, rastgele, minimum 3 palet, maksimum 10 palet olacak şekilde çıkartılıp kullanıcı sahaya iletilir.

Statik durumun dezavantajları yazılan bu program sayesinde ayrıntılı olarak şu şekilde açıklanabilir;

- Yarı dolu peron sayısı fazladır.

- $\quad$ Forkliftçi iş yükü en yakın adrese atama durumu olmadığı için fazladır.

- Yeni karışım kodlarına yer bulunamamaktadır.

- Üretimin fazla olduğu dönemlerde depolama alanı bulmak zorlaşmaktadır.

Yukarıda bahsedilen kurallara ve çalışma prensibine göre elde edilen programın ekran görüntüsü Şekil 1'de verilmiştir.

\section{Aşama: İyileştirme olarak sunulan dinamik adreslemenin kodlanması}

Dinamik adresleme için yazılan programın çalışma prensibi;

- $\quad$ Rastgele kod atanan peronlara yukarıda bahsedilen a(i), b(i), c(i) vb. parametreler sayesinde rastgele maksimum 4 adet önceki günden kalan palet miktarı atanır.
Mikserden çıkan paletler eğer peronlarda var olan bir koda sahipse ve peron kapasitesi yeterli ise öncelikli olarak bu peronlara atama yapılır. Eğer yine Mikserden çıkan paletle aynı karışım koduna sahip bir peron varsa fakat kapasite olarak yetersiz ise o palet en yakın boş perona atanır. Eğer Mikserden çıkan paletle aynı karışım koduna sahip bir peron yok ise en yakın boş peron bu karışımla doldurulmaya başlanır. Bunun kodlanmasının sebebi yarı dolu peron sayısını azaltmaktır.

- Her Mikserden rastgele minimum 110 palet çıkacak şekilde rastgele palet çıkar.

Peronda bulunan paletler, rastgele, minimum 3 maksimum 10 palet olacak şekilde çıkartılır. Fakat burada dikkat edilen bazı kıstaslar bulunmaktadır. Bunlardan ilki, eğer bir karışım koduna ait başka bir peron yoksa aynı statikte olduğu gibi normal bir şekilde çıkışlar sağlanır. İkinci olarak, eğer bir karışım koduna ait başka peronlarda varsa öncelikli olarak yarı dolu peron sayısını azaltmak amaçlı kapasitesi az olandan palet çıkartılarak kullanıcı sahalara iletilir.

Dinamik adresleme avantajları yazılan program sayesinde ayrıntılı olarak şu şekilde açıklanabilir;

- Hiçbir karışım kodunun kendine ait peronu bulunmamaktadır. Bu sebeple üretimde olmayan veya talebi sık olmayan karışım kodları için yer ayrilmamaktadir.

- En yakın atama prensibi nedeniyle forkliftçi iş yükü azalır.

- Yarı dolu peron sayısı azaltılır. Bu sayede kapasitenin verimli kullanılması sağlanır.

- Yeni karışım kodları için rahatlıkla yer bulunabilir.

Statik adreslemenin dezavantajlarını ortadan kaldırmak, daha verimli bir depo alanı oluşturmak için belirlenen kurallara göre elde edilen programın ekran görüntüsü Şekil 2 'de verilmiştir.

Yazılan her iki programda da Tab2 sayfas1 raporlama sayfas1 olarak adlandırılır. Bu sayfa, günlük olarak her perona giren ve çıkan palet sayısını göstermektedir. Giren palet miktarlarını bulurken tq(i) parametresini programdan çekerek, çıkan palet miktarını bulurken tw(i) parametresini programdan çekerek bu işlem gerçekleştirilir. Raporlama sayfası Şekil 3'de verilmiştir. 
ŞMENŞUR

Academic Platform Journal of Engineering and Science 7-3, 481-488, 2019

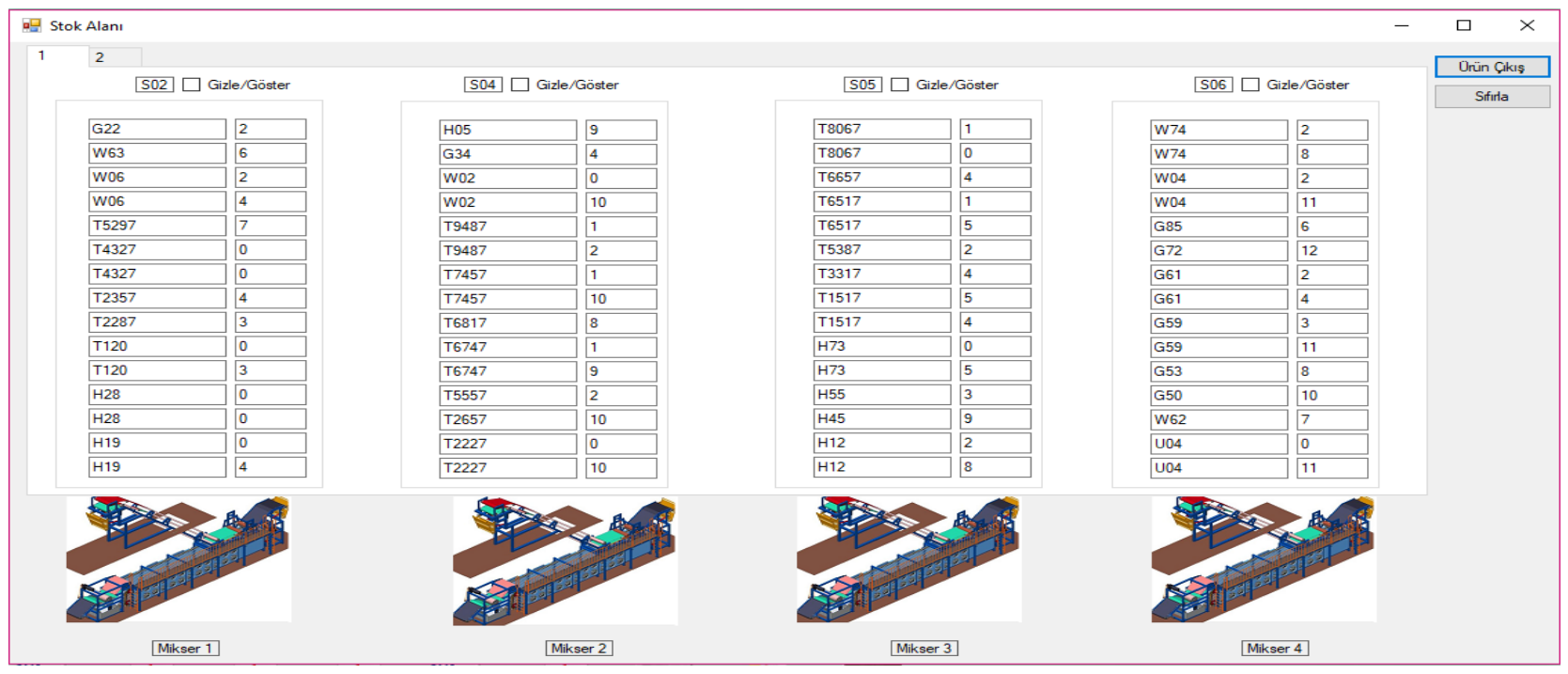

Şekil 1. Statik adresleme ekran görüntüsü

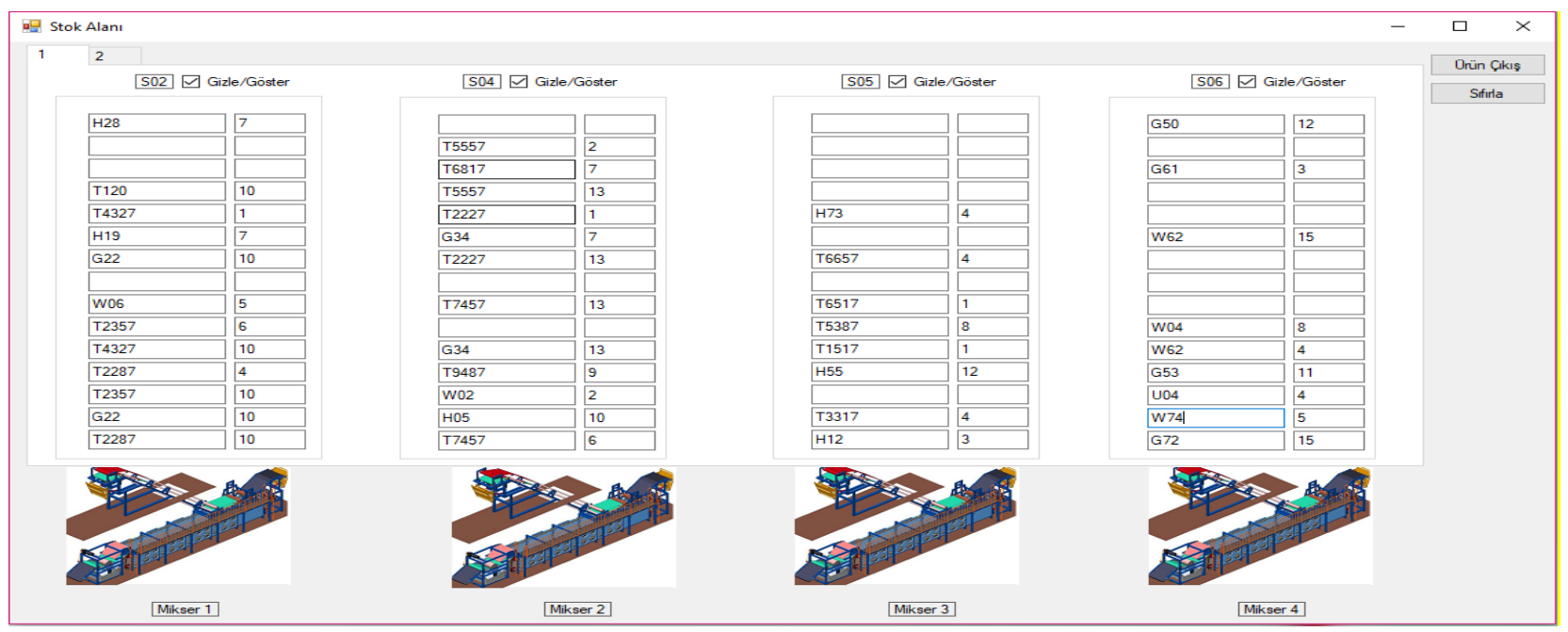

Şekil 2. Dinamik adresleme ekran görüntüsü

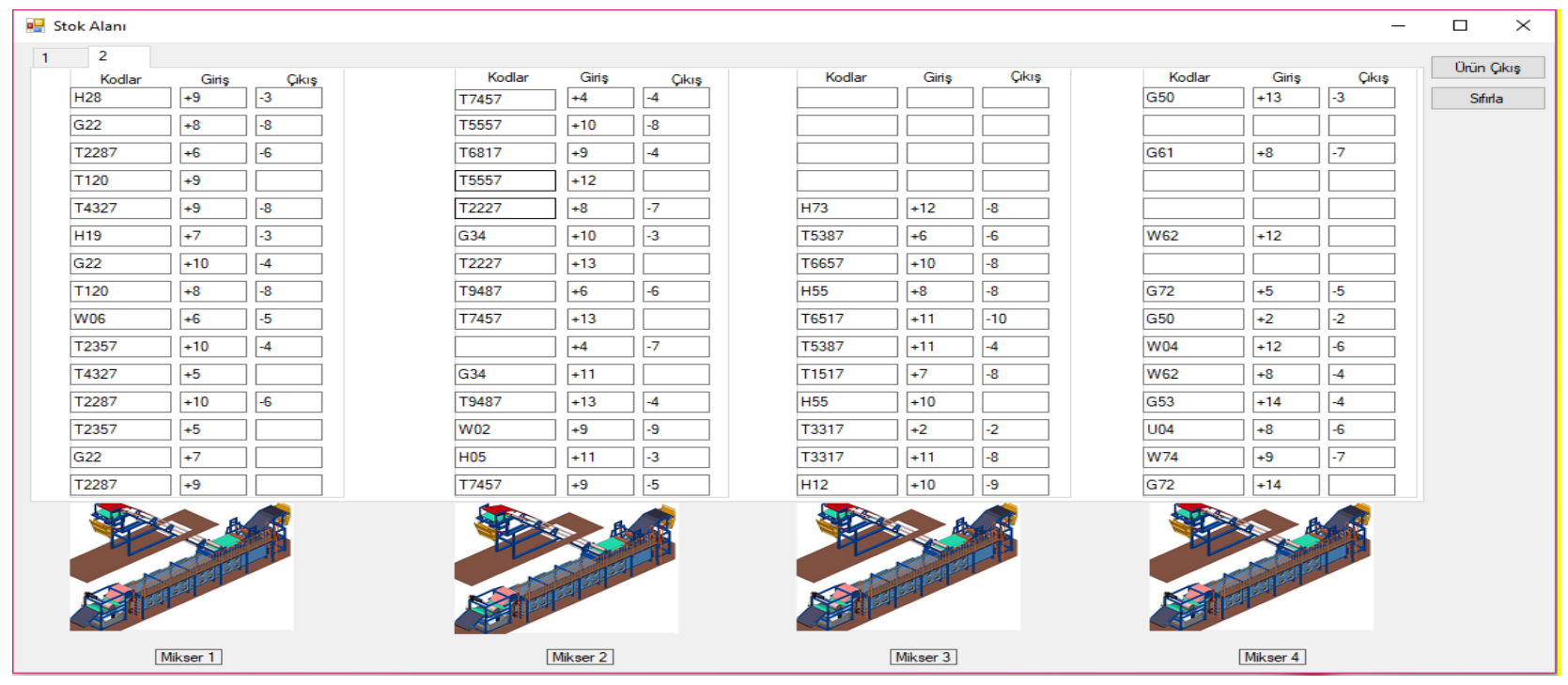

Şekil 3. Dinamik adresleme raporlama

486 


\section{SONUÇLAR}

$\mathrm{Bu}$ aşamada programlar çalıştırılarak istatistiki veri toplanmıştır. İstatistik analiz yaparken kullanılacak verilerin toplanması için yazılan statik ve dinamik adresleme programları art arda $\mathrm{n}=30 \mathrm{kez}$ çalıştıılıp elde edilen sonuçlar tablolarda toplanmıştır. Elde edilen özet bilgiler aşağıdaki Tablo 1'de verilmiştir.

Son olarak toplanan veriler analiz edilip, sonuçları karşılaş̧ırılmıştır. Hangi istatistiki analiz metodunun kullanılacağına karar verilirken $\mathrm{n}=30$ olması ve dinamik adreslemenin statik adreslemeye göre ne kadar iyileşme sağladığının saptanmak istenmesi göz önünde bulundurulmuştur. Bahsedilen durumlara uygun olan yöntemin eşli T-testi olmasına karar verilmiştir. Yapılan T-

Tablo 1. Yarı dolu peron sayısının karşılaştırılması

\begin{tabular}{|c|c|c|}
\hline $\begin{array}{c}\text { Yarı Dolu } \\
\text { Peron Sayı1 }\end{array}$ & $\begin{array}{c}\text { Statik } \\
\text { Adreslemeye } \\
\text { Göre }\end{array}$ & $\begin{array}{c}\text { Dinamik } \\
\text { Adreslemeye } \\
\text { Göre }\end{array}$ \\
\hline Mikser 1 & 372 & 204 \\
\hline Mikser 2 & 402 & 247 \\
\hline Mikser 3 & 405 & 236 \\
\hline Mikser 4 & 408 & 274 \\
\hline
\end{tabular}

testi sonucunda yarı dolu peron sayısı için elde edilen değer 0,000292881 olarak bulunmuştur. Bulunan sayı 0,05 'den küçük olduğu için şu yorum yapılabilmektedir; dinamik adresleme ile statik adresleme arasında önemli derecede bir fark vardır. Bu farklar Şekil 4 ve Şekil 5'deki grafiklerde göz önüne serilmiştir.

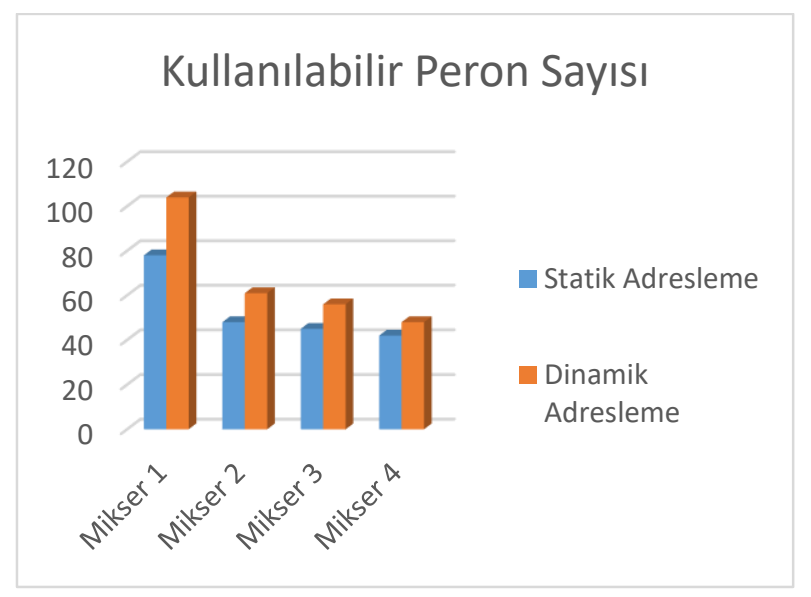

Şekil 4. Kullanılabilir peron sayısının Mikser bazında karşılaştırılması

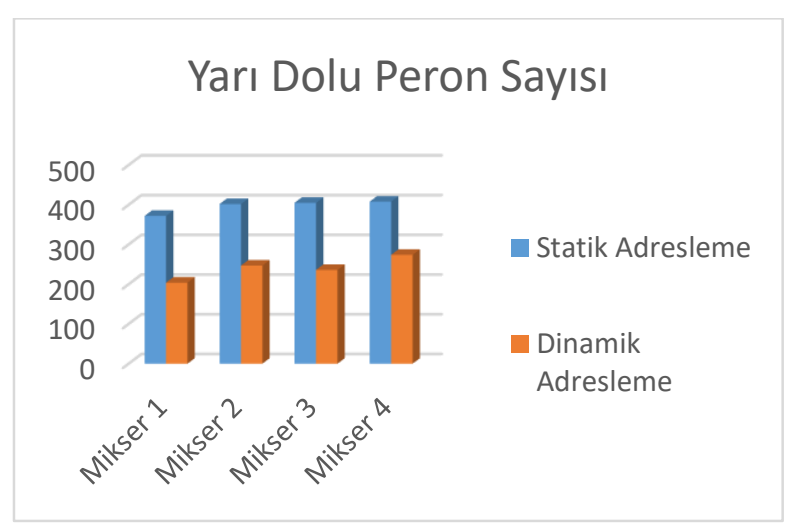

Şekil 5. Yarı dolu peron sayısının Mikser bazında
karşılaştırılması

$\mathrm{Bu}$ çalışmasının sonucunda elde edilen çıktılar için şunlar söylenebilir; kullanılan dinamik programlama yöntemi ile yazılan program ile yarı dolu peron sayısı azaltılmış, bu sayede kapasitenin daha verimli kullanılması sağlanmıştır. Statik adreslemedeki yarı dolu peron sayıs1 1587 iken dinamik adresleme sayesinde bu say1 961 perona gerilemiştir. Dinamik adresleme algoritması yazilırken, forkliftçi iş yükünü azaltmaya yönelik Miksere en yakın perona palet atanması stratejisi göz önünde bulundurulmuştur. Dinamik adresleme sayesinde kullanılmayan karışım kodları için yer ayrılmamaktadır. $\mathrm{Bu}$ sayede kapasite statik adreslemeye göre daha verimli kullanılmaktadır. Kullanılabilir peron sayısı dinamik adresleme sayesinde 213 perondan, 269 perona çıkartılmıştır. Bu sayede yeni karışım kodları için depolama alanı bulmak kolaylaşmıştır. Aynı zamanda benzer yerleşim problemlerinde dinamik programlama ile etkili sonuçlar alınabileceği gibi başka yaklaşımlar ile de kıyaslamalar yapılarak araştırmacılara yeni araştırma alanları sağlayacaktır.

\section{KAYNAKÇA}

[1] C.H. Akarsu, "Atölye Tipi Çizelgeleme Problemleri İçin Genetik Algoritma Tabanlı Hipersezgisel Yaklaşım", İstanbul Üniversitesi, 2018.

[2] A. Alp, H. Çerçioğlu, M. A. Tokaylı, B. Dengiz, "Stokastik Montaj Hattı Dengeleme: Bir Tavlama Benzetimi Algoritması", Endüstri Mühendisliği Dergisi Cilt: 12 Sayı: 3-4 Sayfa: (32-51), 2016.

[3] M. Arıkan, S. Erol, "Bir Tabu Arama Uygulaması: Esnek İmalat Sistemlerinde Parça Seçimi ve Takım Magazini Yerleşimi”, Gazi Üniversitesi Mühendislik ve Mimarlık Fakültesi Dergisi, Cilt No: 21 No:2 221-227, 2006.

[4] K.R. Baker, \& D. Trietsch, Principles of Sequencing and Scheduling, Wiley, 2016.

[5] R. Conway, W. Maxwell, \& L. Miller, Theory of Scheduling, Addison-Wesley, 2016.

[6] T. Eren, E. Güner, "Çok Ölçütlü Akış Tipi Çizelgeleme Problemleri İçin Bir Literatür Taraması", Pamukkale 
Üniversitesi Mühendislik Fakültesi Mühendislik Bilimleri Dergisi, Cilt 10, Sayı 1, 19-30, 2004.

[7] T. Eren, E. Güner, "Tek ve Paralel Makineli Problemlerde Çok Ölçütlü Çizelgeleme İçin Bir Literatür Taraması", J. Fac.Eng.Arch. Selcuk Univ., Volume.21, Number.1-2, 2006.

[8] İ. Gerdemeli, Transport Tekniği Ders Notları 3, İstanbul Teknik Üniversitesi, 2014.

[9] Ö. İşçi, S. Korukoğlu, "Genetik Algoritma Yaklaşımı ve Yöneylem Araştırmasında Bir Uygulama”, Yönetim ve Ekonomi, Celal Bayar Üniversitesi İktisadi ve İdari Bilimler Dergisi, Cilt 10, Say1 2, 191 - 208, 2003.

[10] S.M. Johnson, "Optimal two- and three-stage production schedules with setup times included", Naval Research Logistics, Vol.1, Issue 1, 61-68, 1954. https://doi.org/10.1002/nav.3800010110 [11] İ. Küçükkoç, Üretim ve Servis Sistemlerinde Planlama ve Çizelgeleme Ders Notları, Balıkesir Üniversitesi, 2017.

[12] M. Held and R. M. Karp, "A Dynamic Programming Approach to Sequencing Problems," Journal of the Society for Industrial and Applied Mathematics, Vol. 10, No. 1, 1962, pp. 196-210. doi:10.1137/0110015

[13] T. Yeniyayla, Malzeme Atama Yöntemleri ve Çoklu Depoya Sınıflandırılmış Aile Grubu Malzeme Atama Modeli, Yüksek Lisans Tezi, Kırıkkale Üniversitesi, 2014 